\title{
6-Thioguanine nucleotide accumulation in erythrocytes during azathioprine treatment for systemic connective tissue diseases: a possible index for monitoring treatment
}

\author{
Kjeld Schmiegelow, Niels Jacob Kriegbaum
}

\begin{abstract}
Background Owing to adverse pharmacokinetics, azathioprine treatment may fail to induce a satisfactory clinical response in systemic connective tissue diseases. The major intracellular cytotoxic metabolites of azathioprine are 6-thioguanine nucleotides (6TGNs).
\end{abstract}

Methods To assess whether the erythrocyte accumulation of 6TGN is a clinically applicable index for monitoring azathioprine treatment, erythrocyte accumulation of 6TGN was measured in patients with rheumatoid arthritis $(n=12)$, systemic lupus erythematosus $(n=7)$, polyarteritis nodosa $(n=2)$, myositis $(n=1)$, or leucocytoclastic vasculitis $(n=1)$. Ages ranged from 28 to 75 (median 58) years.

Results Erythrocyte accumulation of 6TGN varied among the patients from 20 to 303 (median value 95 ) $\mathbf{n m o l} / \mathrm{mmol}$ haemoglobin. No significant correlation was found between erythrocyte accumulation of 6TGN and the dose of azathioprine/ $\mathrm{kg}$ body weight, the age of the patients, the duration of treatment, or the presence of myelotoxicity or hepatotoxicity. The interindividual coefficient of variation $(\mathrm{CV})$ in the erythrocyte accumulation of $6 \mathrm{TGN} / \mathrm{mg}$ azathioprine/kg body weight was 0.65. The median intraindividual $\mathrm{CV}$ in erythrocyte accumulation of 6TGN at an unchanged dose of azathioprine was 0.09 (19 patients; range $0.03-0.27$ )

Conclusions The low intraindividual variation compared with the high interpatient variation in erythrocyte accumulation of 6TGN implies that erythrocyte accumulation of 6TGN may be clinically applicable for monitoring azathioprine treatment. Prospective studies are needed to clarify the relation between the erythrocyte accumulation of 6TGN and the clinical response to treatment, and to establish recommendations for dose modifications.

(Ann Rheum Dis 1993; 52: 152-154)

For more than 20 years the thiopurine analogue azathioprine has been used to treat systemic connective tissue diseases. ${ }^{1-3}$ The response to azathioprine treatment is unpredictable, however, and often disappointing and the optimal regimen for individual dose adjustments has still to be established.

The thiopurines are prodrugs with considerable and clinically relevant interindividual variations in their metabolism. ${ }^{4}$ After absorption, azathioprine is cleaved to 6-mercaptopurine, which, after several metabolic steps, is incorporated into DNA and RNA as 6-thioguanine nucleotides (6TGNs), thereby mediating the cytotoxic and immunosuppressive effects of azathioprine. ${ }^{46}$ During thiopurine treatment, 6TGN accumulates in cells, including erythrocytes. ${ }^{7}$ As erythrocyte accumulation of 6TGN may reflect systemic exposure to thiopurine as well as the individual patient's ability to accummulate 6TGN, erythrocyte accumulation of 6TGN could be an index of intensity of treatment. ${ }^{7-9}$ As part of a continuing study to evaluate the possible usefulnesss of erythrocyte accumulation of 6TGN as a guide for adjustments of dose of azathioprine in patients with systemic connective tissue diseases, we report on the inter- and intraindividual variations in erythrocyte accumulation of $6 \mathrm{TGN}$ in relation to the characteristics of patients and to toxicity.

\section{Patients and methods}

\section{PATIENTS}

We studied 23 patients with systemic connective tissue diseases who were treated with azathioprine at the medical department TTA, University Hospital, Copenhagen. The table gives the data on patients. All had normal kidney function as measured by serum creatinine.

\section{TREATMENT}

The table and the figure give the characteristics of azathioprine treatment. For all patients the dose of azathioprine was unchanged during the study period. As well as azathioprine, 13 patients received prednisone throughout the study and six patients received non-steroidal anti-inflammatory drugs. Otherwise the patients received no drugs known to affect disease activity or metabolism of azathioprine.

\section{RESPONSE TO TREATMENT}

As the design of the study was retrospective and the clinical response to azathioprine was not uniformly registered, it was not possible to assess reliably the response to azathioprine treatment. The correlations between erythrocyte accumulation of 6TGN and the following 
Characteristics of patients

\begin{tabular}{|c|c|c|c|c|c|c|c|c|}
\hline \multirow[t]{2}{*}{ Diagnosis } & \multirow[t]{2}{*}{ Sex } & \multirow{2}{*}{$\begin{array}{l}\text { Age } \\
\text { (years) }\end{array}$} & \multirow{2}{*}{$\begin{array}{l}\text { Duration } \\
\text { of SCTD } \\
\text { (years) }\end{array}$} & \multirow{2}{*}{$\begin{array}{l}\text { Starting" } \\
\text { dose } \\
\text { PRED } \\
(\mathrm{mg} / \mathrm{kg})\end{array}$} & \multirow{2}{*}{$\begin{array}{l}\text { Starting } \\
\text { dose } \\
A Z A \\
(m g / k g)\end{array}$} & \multirow{2}{*}{$\begin{array}{l}\text { Years of } \\
\text { AZA } \\
\text { treatment }\end{array}$} & \multicolumn{2}{|l|}{ At study period } \\
\hline & & & & & & & $\begin{array}{l}\text { Dose PRED } \\
(\mathrm{mg} / \mathrm{kg})\end{array}$ & $\begin{array}{l}\text { Mean E-6TGN+l } \\
m g \text { AZA/kg }\end{array}$ \\
\hline $\begin{array}{l}\text { RA } \\
\text { RA } \\
\text { RA } \\
\text { RA } \\
\text { RA } \\
\text { RA } \\
\text { RA } \\
\text { RA } \\
\text { RA } \\
\text { RA } \\
\text { RA } \\
\text { RA } \\
\text { SLE } \\
\text { SLE } \\
\text { SLE } \\
\text { SLE } \\
\text { SLE } \\
\text { SLE } \\
\text { SLE } \\
\text { PAN } \\
\text { PAN } \\
\text { Leu vas } \\
\text { MYO }\end{array}$ & $\begin{array}{l}M \\
M \\
W \\
W \\
W \\
W \\
W \\
M \\
M \\
W \\
W \\
W \\
W \\
W \\
W \\
W \\
W \\
W \\
W \\
W \\
W \\
M \\
W \\
W\end{array}$ & $\begin{array}{l}41 \\
54 \\
57 \\
65 \\
65 \\
66 \\
66 \\
67 \\
69 \\
69 \\
73 \\
75 \\
29 \\
37 \\
41 \\
43 \\
43 \\
47 \\
48 \\
28 \\
63 \\
42 \\
59\end{array}$ & $\begin{array}{r}25 \\
33 \\
42 \\
7 \\
36 \\
39 \\
9 \\
13 \\
35 \\
11 \\
19 \\
21 \\
9 \\
24 \\
13 \\
20 \\
15 \\
17 \\
9 \\
5 \\
18 \\
8 \\
29\end{array}$ & $\begin{array}{l}0 \cdot 20 \\
0 \cdot 28 \\
\\
\\
0.08 \\
0 \cdot 15 \\
0 \cdot 35 \\
\\
0 \cdot 45 \\
\\
0.56 \\
0 \cdot 25 \\
0 \cdot 72 \\
0 \cdot 32 \\
0.51 \\
0 \cdot 20 \\
1.20 \\
1.67 \\
0.98 \\
0.64 \\
0.18\end{array}$ & $\begin{array}{l}1.3 \\
1.4 \\
1.4 \\
1.3 \\
1.6 \\
1.8 \\
2.5 \\
1.5 \\
2.5 \\
2.6 \\
1.8 \\
3.2 \\
2.1 \\
2.5 \\
2.4 \\
2.3 \\
2.6 \\
1.4 \\
1.7 \\
2.5 \\
1.5 \\
0.8 \\
1.8\end{array}$ & $\begin{array}{r}2 \\
5 \\
7 \\
4 \\
7 \\
8 \\
2 \\
7 \\
17 \\
5 \\
2 \\
8 \\
9 \\
4 \\
1 \\
16 \\
2 \\
4 \\
4 \\
3 \\
4 \\
3 \\
9\end{array}$ & $\begin{array}{l}0 \cdot 10 \\
0 \cdot 14 \\
\\
\\
0 \cdot 00 \\
0 \cdot 15 \\
0 \cdot 09 \\
\\
0 \cdot 14 \\
\\
0 \cdot 11 \\
0 \cdot 21 \\
0 \cdot 24 \\
0 \cdot 08 \\
0 \cdot 08 \\
0 \cdot 00 \\
0 \cdot 18 \\
0 \cdot 33 \\
0 \cdot 00 \\
0 \cdot 00 \\
0 \cdot 00\end{array}$ & $\begin{array}{r}89 \\
107 \\
14 \\
32 \\
51 \\
32 \\
81 \\
48 \\
233 \\
48 \\
40 \\
71 \\
61 \\
26 \\
53 \\
86 \\
60 \\
112 \\
91 \\
38 \\
151 \\
46 \\
80\end{array}$ \\
\hline
\end{tabular}

RA= Rheumatoid arthritis; E-6TGN=erythrocyte accumulation of 6TGN; SLE=systemic lupus erythematosus; PAN=polyarteritis nodosa; Leu vas=leucocytoclastic vasculitis; $M Y O=$ myositis; $W=$ woman; $M=\operatorname{man} ; S C T D=$ systemic connective tissue disease PRED= prednisone; AZA = azathioprine

${ }^{*}$ Dose of steroids and azathioprine when azathioprine treatment was initiated.

† Mean erythrocyte accumulation of 6-thioguanine nucleotides at an unchanged dose of azathioprine ( $\mathrm{nmol} / \mathrm{mmol}$ haemoglobin).

indices were calculated: haemoglobin, white cell count, absolute neutrophil count, lymphocyte count, thrombocyte count, erythrocyte sedimentation rate, $C$ reactive protein concentrations, level of antibodies to DNA, and serum aminotransferase activity. For each patient a mean of all measurements available during the study period for each of these variables was calculated.

Erythrocyte accumulation of 6TGN was measured by high performance liquid chromatography as described elsewhere. ${ }^{10}$ The within and between run coefficients of variation (CVs) of the assay were between 5 and $7 \%$. Erythrocyte accumulation of 6TGN was always assayed in duplicate and expressed as nmol 6TGN/mmol haemoglobin. At an unchanged dose of azathio-

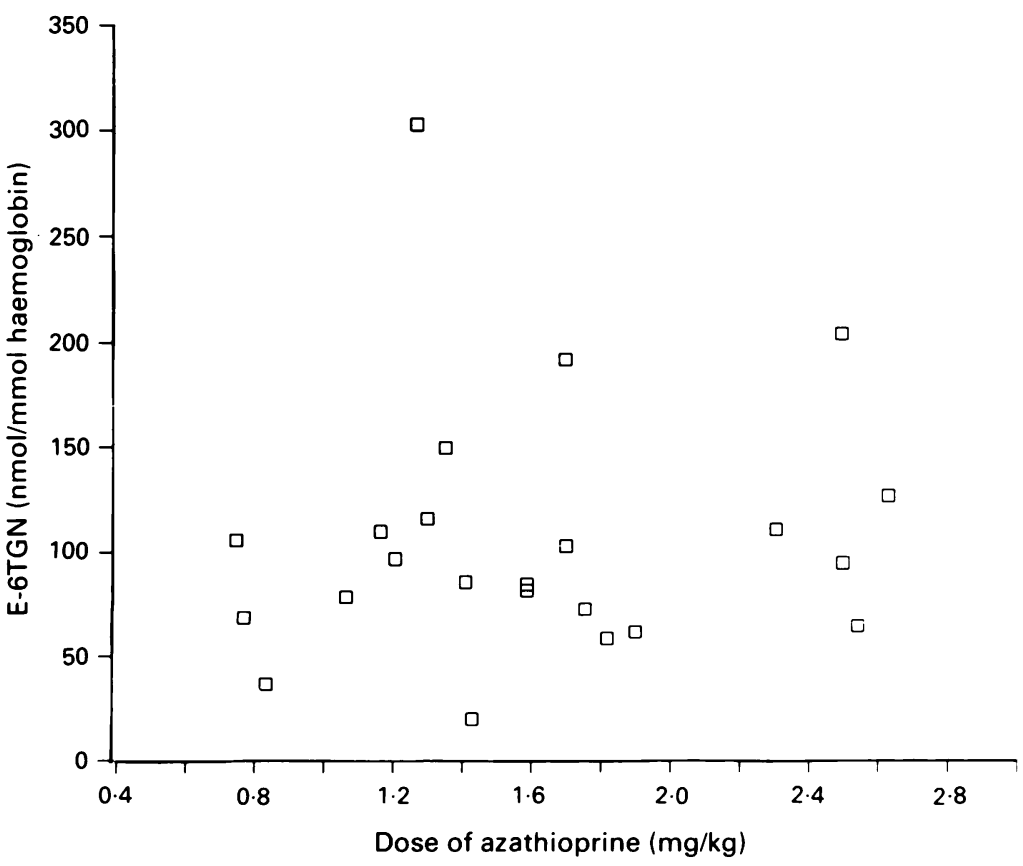

Scattergram of steady state levels of the erythrocyte accumulation of 6-thioguanine nucleotides (E-6TGNs) in relation to the daily oral dose of azathioprine/kg body weight. prine, erythrocyte accumulation of 6TGN was measured once in four patients, twice in three patients, three times in 14 patients, and four times in two patients. A mean of these measurements was calculated for each patient.

\section{STATISTICAL ANALYSIS}

Subgroups were compared for differences in specified variables with the Mann-Whitney rank sum test. The correlation between variables was tested with Spearman's non-parametric rank correlation analysis $\left(r_{\mathrm{s}}=\right.$ Spearman's correlation coefficient). Values of $p<0.05$ were regarded as statistically significant.

\section{Results}

Mean erythrocyte accumulation of 6TGN varied among the patients from 20 to 303 $\mathrm{nmol} / \mathrm{mmol}$ haemoglobin (median value 95; figure). The erythrocyte accumulation of 6TGN in relation to the prescribed dose of azathioprine (mean erythrocyte accumulation of $6 \mathrm{TGN} / \mathrm{mg}$ azathioprine $/ \mathrm{kg}$ body weight) ranged from 14 to $233 \mathrm{nmol} / \mathrm{mmol}$ haemoglobin $/ \mathrm{mg}$ azathioprine/kg (median value 60 ) with an interindividual $\mathrm{CV}$ of 0.65 . The erythrocyte accumulation of $6 \mathrm{TGN} / \mathrm{mg}$ azathioprine $/ \mathrm{kg}$ was not significantly related to duration of disease, age, concurrent administration of prednisone, the total preceding period of azathioprine treatment, or the haemoglobin concentration. Mean erythrocyte accumulation of 6TGN was not significantly related to the dose of azathioprine $/ \mathrm{kg}$ ( $\mathrm{p}=0.36$; figure). Men had a higher erythrocyte accumulation of $6 \mathrm{TGN} / \mathrm{mg}$ azathioprine $/ \mathrm{kg}$ than women $(\mathrm{p}=0.0 \mathrm{l}$; table). The median intraindividual $\mathrm{CV}$ of erythrocyte accumulation of 6TGN at an unchanged dose of azathioprine was 0.09 (19 patients; range 0.03$0 \cdot 27$ ), and this was not significantly related to erythrocyte accumulation of 6TGN, haemoglobin, the dose of azathioprine, the number of 
measurements of erythrocyte accumulation of 6TGN, or sex.

The prevalence of myelotoxicity was low. When all patients were included, the median platelet count was $288 \times 10^{9} / 1$, the median white blood cell count $6.4 \times 10^{9} / 1$, the median absolute neutrophil count $4.7 \times 10^{9} / 1$, and the median lymphocyte count $1 \cdot 0 \times 10^{9} / 1$. No significant correlations between erythrocyte accumulation of $6 \mathrm{TGN}$ and the haematological variables were found for the total study group or for disease subgroups. No patients had serum aminotransferase activity above the upper normal limit (40 IU/l). No correlations were found between mean erythrocyte accumulation of 6TGN and the sedimentation rate or $\mathrm{C}$ reactive protein concentration. All three patients with systemic lupus erythematosus and anti-DNA levels $>10$ IU/1 had mean erythrocyte accumulation of $6 \mathrm{TGN}$ of $<90 \mathrm{nmol} / \mathrm{mmol}$ haemoglobin.

\section{Discussion}

For several decades azathioprine treatment has been used to induce remissions or reduce the need for prednisone in patients with systemic connective tissue diseases. A major reason for failures of azathioprine treatment might be individual variations in thiopurine pharmacokinetics reflecting a complex integration of genetically and behaviourally determined factors. ${ }^{11} 12$ Owing to the small intraindividual and large interindividual variations in erythrocyte accumulation of 6TGN found in the present study, ranking according to the amount of erythrocyte accumulation of 6TGN with a single or a few measurements of erythrocyte accumulation of 6TGN is possible. Most of the patients in this study had far lower erythrocyte accumulation of 6TGN values than those necessary for 6-mercaptopurine to induce optimal treatment results in acute lymphoblastic leukaemia in childhood. ${ }^{12}$ Although it remains to be determined whether failures of azathioprine treatment in patients with systemic connective tissue diseases are similarly due to adverse drug metabolism and are reflected in low erythrocyte accumulation of 6TGN, the interindividual differences in pharmacokinetics do imply variations in treatment intensity at similar drug dosage. Hence indices are needed that reflect these differences and that may serve as guidelines for adjustments of dose.

Because lymphocytes lack xanthine oxidase, a major enzyme in thiopurine metabolism with little interindividual variation in activity, ${ }^{13}$ concentrations of 6TGN may be higher in erythrocytes than in lymphocytes; however, as in vivo data on leucocyte-6TGN are lacking the clinical significance of this is unknown.

As none of the patients showed clinical myeloor hepatotoxicity, increases in dose would have been possible in most cases. Treating to toxicity may not always be necessary, however, as several of the patients with the highest erythrocyte accumulation of 6TGN in the present study had a satisfactory clinical response and still only moderate or no signs of toxicity. Until the applicability and clinical value of erythrocyte accumulation of 6TGN as a guideline for adjustments of that dose of azathioprine have been prospectively evaluated, we recommend that the dose of azathioprine be increased for patients not responding to standard doses and in whom dose limiting hepato- or myelotoxicity has not developed.

The skilful technical assistance of Michael Timm is greatly acknowledged.

1 Urowitz M B, Smythe H A, Able T, et al. Azathioprine treatment of rheumatoid arthritis (RA)-double-blind crossover study. Arthritis Rheum 1971; 14: 419.

2 Sztejnbok M, Stewart A, Diamond H, Kaplan D. Azathio prine in the treatment of systemic lupus erythematosus. Arthritis Rheum 1971; 14: 639-45.

3 Sambrook P N, Champion G D, Browne C D, et al. Comparison of methotrexate with azathioprine or 6-mercaptopurine in refractory rheumatoid arthritis: a life-table analysis. Br f Rheumatol 1986; 25: 372-5.

4 van Scoik K G, Johnson C A. The pharmacology and metabolism of the thiopurine drugs 6-mercaptopurine and metabolism of the thiopurine drugs 6-mercaptop

5 Chan G L C, Erdmann G R, Gruber S A, et al. Pharmacokinetics of 6-thiouric acid and 6-mercaptopurine in renal allograft recipients after oral administration of azathioprine. Eur f Clin Pharmacol 1989; 36: 265-71.

6 Grant L D, Kaesberg P R, Ershler W B. Immunologica effects of cancer chemotherapy. In: Powis G, Hacker M P eds. The toxicity of anticancer drugs. New York: Pergamon Press, 1991: 167-97.

7 Schmiegelow K, Bruunshuus I. 6-thioguanine nucleotide accumulation in red blood cells during maintenance chemotherapy for childhood acute lymphoblastic leukemoits 1990; 26: 288-92.

8 Lennard L, Lilleyman J S, Loon J, Weinshilboum R M. Genetic variation in response to 6-mercaptopurine for Genetic variation in response to 6-mercaptopurine for
childhood acute lymphoblastic leukemia. Lancet 1990; childh 9 .

9 Lennard L, Brown C B, Fox M, Maddocks J L. Azathioprine metabolism in kidney transplant recipients. $\mathrm{Br} \mathcal{F}$ Clin Pharmacol 1984; 18: 693-700.

10 Bruunshuus I, Schmiegelow K. Analysis of 6-mercaptopurine 6-thioguanine nucleotides, and 6-thiouric acid in biologica fluids by high performance liquid chromatography. Scand f Clin Lab Invest 1989; 49: 779-84.

11 Weinshilboum R. Pharmacogenetics of methylation: relationship to drug metabolism. Clin Biochem 1988; 21: 201-10.

12 Schmiegelow $\mathrm{K}$. Implications of intracellular pharmacokinetics and metabolism of MTX and 6MP in red blood cells during maintenance therapy for childhood acute lymphoblastic leukemia. In: Riccardi $R$, Borsi J, eds. The role of clinical pharmacology in pediatric oncology. 1991: role of

13 Elion G B. Interaction of anticancer drugs with enzymes. In Pharmacological basis of cancer chemotherapy. Baltimore: Williams and Wilkins, 1975: 547-64. 